Revista Iberoamericana, Vol. LXXII, Núm. 214, Enero-Marzo 2006, 49-59

\title{
LA REVISTA, EL PERIÓDICO Y SUS LECTORES EN EL CHILE DECIMONÓNICO ${ }^{1}$
}

\author{
POR \\ Juan Poblete \\ University of California, Santa Cruz
}

La Revista Católica advertía tempranamente en 1843 que algo comenzaba a cambiar de manera notoria en la cantidad, calidad y formas de circulación de los textos impresos en Chile:

Es sin duda laudable en gran manera la afición progresiva que muestra la juventud chilena a la lectura de los nuevos libros que cada día nos envía la Europa. Pero ésta así como otras inclinaciones de los jóvenes es preciso que sea bien dirigida para que pueda producir saludables resultados. No basta leer solamente: se necesita también de una especie de tino para elejir los libros que deben leerse, de lo contrario nos esponemos a gastar el tiempo sin provecho y quizás con grande perjuicio nuestro. (2:14)

Cabe advertir que estas palabras son también contemporáneas del despertar cultural chileno normalmente descrito bajo el nombre de Generación de 1842 que, entre otras cosas, había recientemente producido las primeras discusiones intelectuales fuertes entre Andrés Bello y José Victorino Lastarria, Bello y Jacinto Chacón, etc. En estas llamadas polémicas de 1842, ampliamente historiadas por la crítica chilena, interesa destacar ahora su caracter intergeneracional. Por vez primera en el país, o así lo parecía a sus actores al menos, los jóvenes se hallaban en posición de discutir no sólo los detalles sino los fundamentos y la in/utilidad del tipo de conocimiento que les era transmitido por sus mayores. La legitimidad misma del saber autorizado era cuestionada. No pequeño papel tenía en ello, la relativa abundancia de nuevas fuentes de autoridad discursiva que el bullente mercado europeo de las ideas ofrecía en la forma de todo tipo de publicaciones (libros, periódicos, revistas).

La mayor abundancia de estos discursos requería, en opinión de la jerarquía católica, una reafirmación de la autoridad exclusiva de la Iglesia para controlar no sólo el flujo y circulación de estos impresos, sino su selección y decodificación apropiada. Como institución, ya desde los comienzos de la colonialidad española en América, la Iglesia se había arrogado el derecho y había estado encargada de dicha tarea censora.

\footnotetext{
${ }^{1}$ El presente trabajo, en una versión ligeramente diferente, forma hoy parte de mi libro Literatura chilena del siglo XIX: entre públicos lectores y figuras autoriales.
} 